\title{
GLOBAL DNA METHYLATION ASSOCIATED WITH MAJOR DEPRESSIVE DISORDER
}

\section{Homorogan 1 , V.R. Enatescu1, A. Marcu², E. Seclaman², C. Marian²}

${ }^{1}$ Victor Babes University of Medicine and Pharmacy Timisoara-Discipline of Psychiatry, Timisoara, Romania and Eduard Pamfil Psychiatry Clinic, Timisoara County Hospital, Timisoara, Romania

2 Victor Babes University of Medicine and Pharmacy Timisoara-Department of Biochemistry, Timisoara, Romania

\section{Background and aims}

Available data suggests that major psychiatric disorders, including depressive disorder, are associated with altered gene expression, which are considered to be caused by altered epigenetic mechanisms, including DNA methylation. We have investigated herein the association of DNA methylation in peripheral nucleated blood cells (PNBCs) with MDD and treatment response.

The objectives of the current study was to assess changes in global DNA methylation in major depressive disorder (MDD) patients undergoing antidepressive treatment and healthy controls.

\section{Materials and methods}

We assessed by ELISA, the level of global DNA methylation in DNA from PNBCs in MDD patients before and after escitalopram treatment, compared with healthy controls. At the initiation and at the end of treatment, blood samples were collected on EDTA anticoagulant and a structured diagnostic interview and a standardized depression rating scale were done.

\section{Results}

In this pilot project, we found a statistical significant difference in the levels of global methylation between MDD patients and healthy controls (Fig. 1). The MDD patients had lower levels of methylation compared to controls, regardless of treatment status $(p=0.034$ for patients before treatment and $p=0.007$ for patients after treatment, compared to controls). There was no difference in methylation associated with the treatment $(p=0.427$ (Table 1)

\section{Conclusions}

In line with certain previous reports, we found lower levels of methylation in the PNBCs of MDD patients compared to controls, and these methylations levels were not affected by antidepressant treatment. This is a pilot project of limited sample size, and therefore these results need replication if future larger studies before definitive conclusions can be drawn.

\begin{tabular}{|c|c|c|c|}
\hline & Controls & Before Treatment & After Treatment \\
\hline $\begin{array}{c}\text { DNA meth \% } \\
(\text { Mean } \pm \text { SD })\end{array}$ & $4.068 \pm 1.168$ & $3.105 \pm 0.782$ & $2.864 \pm 0.677$ \\
\hline ANOVA p value & \multicolumn{3}{|c|}{0.0092} \\
\hline $\begin{array}{c}\text { B vs Ctrl } \\
\text { t test p value }\end{array}$ & \multicolumn{2}{|r|}{0.0343} & \\
\hline $\begin{array}{c}\text { B vs A } \\
\text { t test p value }\end{array}$ & & \multicolumn{2}{|c|}{0.4275} \\
\hline $\begin{array}{c}\text { A vs Ctrl } \\
\text { t test p value }\end{array}$ & & & 0.0078 \\
\hline
\end{tabular}

Table. 1. DNA methilation in patients with major depressive disorder, before and after antidepressive treatment, compared to controls.

Legend: $B=b e f o r e ~ t r e a t m e n t, A=a f t e r$ treatment, $C t r l=c o n t r o l s$

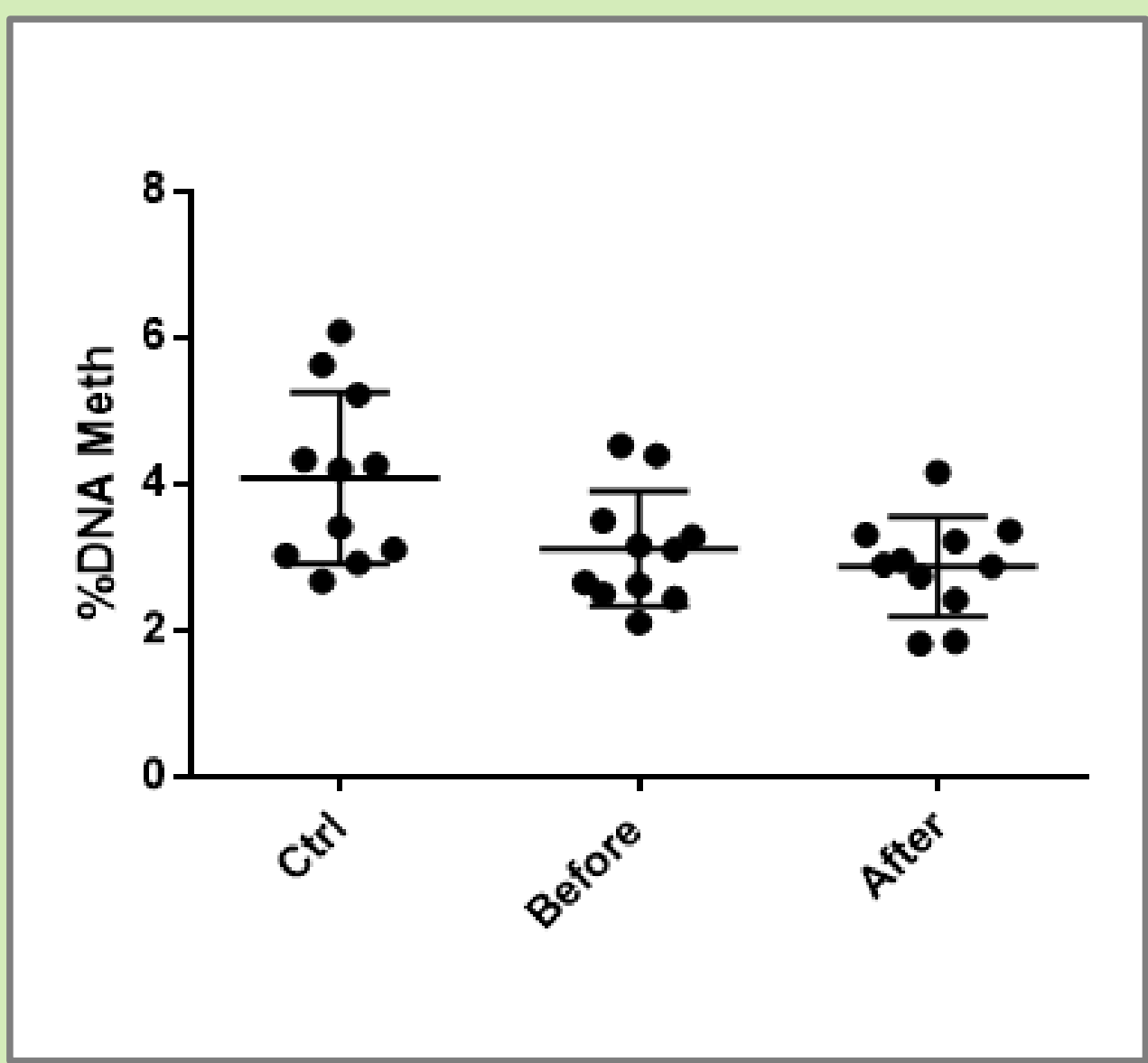

Fig. 1. DNA methilation, controls and patients - before and after antidepressive treatment 